\title{
An experimental study of the dual-fuel performance of a small compression ignition diesel engine operating with three gaseous fuels
}

\author{
J Stewart $^{1}$, A Clarke ${ }^{2 *}$, and $\mathbf{R}$ Chen $^{1}$ \\ ${ }^{1}$ Department of Aeronautical and Automotive Engineering, University of Loughborough, Loughborough, UK \\ ${ }^{2}$ Wolfson School of Mechanical and Manufacturing Engineering, University of Loughborough, Loughborough, UK
}

The manuscript was received on 11 October 2006 and was accepted after revision for publication on 7 June 2007.

DOI: 10.1243/09544070JAUTO458

\begin{abstract}
A dual-fuel engine is a compression ignition (CI) engine where the primary gaseous fuel source is premixed with air as it enters the combustion chamber. This homogenous mixture is ignited by a small quantity of diesel, the 'pilot', that is injected towards the end of the compression stroke. In the present study, a direct-injection CI engine, was fuelled with three different gaseous fuels: methane, propane, and butane. The engine performance at various gaseous concentrations was recorded at $1500 \mathrm{r} / \mathrm{min}$ and quarter, half, and three-quarters relative to full a load of $18.7 \mathrm{~kW}$. In order to investigate the combustion performance, a novel three-zone heat release rate analysis was applied to the data. The resulting heat release rate data are used to aid understanding of the performance characteristics of the engine in dual-fuel mode.

Data are presented for the heat release rates, effects of engine load and speed, brake specific energy consumption of the engine, and combustion phasing of the three different primary gaseous fuels.

Methane permitted the maximum energy substitution, relative to diesel, and yielded the most significant reductions in $\mathrm{CO}_{2}$. However, propane also had significant reductions in $\mathrm{CO}_{2}$ but had an increased diffusional combustion stage which may lend itself to the modern high-speed direct-injection engine.
\end{abstract}

Keywords: dual-fuel, alternative gaseous fuels, three-zone heat release analysis, combustion phasing, carbon dioxide $\left(\mathrm{CO}_{2}\right)$ reductions

\section{INTRODUCTION}

The term 'dual fuel' refers to a compression ignition (CI) engine where a homogenous mixture of gaseous fuel and air is ingested. The ignition source is the injection of a small quantity of diesel fuel, and the overall combustion process is similar to that of a diesel engine. The objective of this technique is to reduce problematic diesel engine emissions of nitrogen oxides $\left(\mathrm{NO}_{x}\right)$ and smoke. The drawback is

* Corresponding author: Wolfson School of Mechanical and Manufacturing Engineering, University of Loughborough, Loughborough, Leicestershire, LE11 3TU, UK. email: a.clarke@ lboro.ac.uk that this reduction is often accompanied by an increase in emissions of carbon monoxide (CO) and unburned hydrocarbons [1].

Karim [2] described the dual-fuel combustion process as proceeding in three stages after ignition in an indirect-injection CI engine. The first stage is due to the combustion of approximately half of the pilot fuel and a small amount of gaseous fuel entrained within it. The second is due to diffusive combustion of the remaining pilot fuel and the rapid burning of gaseous fuel in the immediate surroundings. The third stage is due to flame propagation through the remainder of the cylinder charge. This description allows some explanation of dual-fuel exhaust emission trends. For example, the formation 
of $\mathrm{NO}_{x}$ is known to be strongly dependent on local temperatures, and so most $\mathrm{NO}_{x}$ would be formed in the region around the pilot spray where high temperatures exist and the equivalence ratio is close to stoichiometric [3].

Dual-fuel engines typically use either natural gasmethane or liquefied petroleum gas (LPG)-propane as the primary fuel [4]. The performances of different gaseous fuels as compared with each other is the subject of this present research, as they have not been directly compared in a modern direct-injection diesel engine. For varions pilot quantity and gaseous fuel concentrations, three different fuels (methane, propane, and butane) are compared as these factors have been identified as amongst the most important parameters influencing the dual-fuel combustion process [5-7]. As the pressures and temperatures of the unburned premixed charge are raised, there is a significant broadening of the flammability limits of the gas-air mixture [8], which aids these engines to run at high premixed gas-to-air fuel ratios.

Methane, the main constituent of natural gas (typically $94 \mathrm{vol} \%$ in the UK), is a preferred fuel for use in dual-fuel engines as it is highly knock resistant and contains more energy per unit mass than other conventional fuels [9], while fuel cost savings generally offset the cost of engine conversion [10]. It is the simplest and most stable hydrocarbon and its gaseous nature allows excellent mixing with air, resulting in an even charge distribution and smoother heat release rates [1]. Methane has a wide flammability range, low global toxicity (in comparison with diesel), and low photochemical reactivity [11]. Most of the unburned hydrocarbon emissions from these types of engine are methane. Although it is chemically resistant and toxicologically inert, it has 12-30 times the greenhouse effect of carbon dioxide $\left(\mathrm{CO}_{2}\right)$ and so requires control $[\mathbf{1 1}]$.

Propane is the main constituent of LPG and is attractive for use in dual-fuel engines as it is a single, relatively simple species; therefore engines and after treatment systems can be designed to utilize it cleanly [12]. It can be stored at atmospheric pressure and so there are no evaporative losses. Propane has a good volumetric energy content and a road octane number of more than 100. Consequently, it is considered that the most suitable use of LPG in engines is via dual fuel rather than bi fuel [13]. Although propane is normally regarded as a fast-reacting fuel, it has an extended ignition delay period compared with methane $[\mathbf{1 4}, \mathbf{1 5}]$ and, although it tends to produce slightly higher power due to the fast burning rates, it is ultimately possible to achieve higher power outputs with the more knock-resistant methane.
Butane (a by-product of gasoline production) has a greater volumetric energy content than propane and it has a relatively low reactivity in the atmosphere [4]. Goto et al. [16] found that a butane-diesel dual-fuel engine had a higher thermal efficiency than when fuelled with propane, and much reduced quantities of diesel were needed for ignition. Almost the same output was achieved with butane as with diesel alone over a wide load range, without smoke, and dual-fuel operation was satisfactory at idle with 70 per cent of the total heating value being supplied by butane. The butane-diesel engine had the same specific fuel consumption and reduced $\mathrm{NO}_{x}$ emissions compared with diesel; however, $\mathrm{CO}$ levels were greatly increased. It was suggested that this effect was caused because butane acts as a reducing agent for $\mathrm{NO}_{x}$ but is itself oxidized to CO.

The primary gaseous fuels examined were chosen to represent compressed natural gas (CNG) and LPG. Propane and butane are both by-products of petroleum refining and therefore are attractive alternative fuel supplies from an economic viewpoint.

\section{EXPERIMENTAL PROCEDURE}

\subsection{Test facility}

The present study focuses on the effect of concentration and type of gaseous fuel, and quantity of diesel pilot on engine performance of a dual-fuel engine. In order to make direct comparisons between the various fuels and operating conditions, the operating conditions (e.g. injection timing) were not optimized. Details of the engine specification are given in Table 1.

The engine was coupled to a Heenan-Dynamatic Mk II $220 \mathrm{~kW}$ eddy current dynamometer which controlled and measured torque and speed, with a maximum error in speed of $\pm 1 \mathrm{r} / \mathrm{min}$ and $\pm 2 \mathrm{Nm}$ in torque. Intake airflow was measured using a laminar viscous flow air meter with a type 5 Cussons manometer. Diesel fuel consumption was recorded using a volumetric fuel measurement system. The installation is shown schematically in Fig. 1(a).

High-speed data, consisting of the cylinder pressure, fuel line pressure and crank angle (CA), were acquired using a National Instruments PCIO-MX16-E PC-BNC rack interface, coupled with a BNC 2090 capture board. The cylinder pressure was measured using a Kistler type 6053B60 piezocapacitive transducer connected to a type 5011 charge amplifier. The dynamic fuel line pressure was obtained using a Kistler 4065A piezoresistive sensor and 4617A amplifier. The data 
Table 1 Engine specifications

\begin{tabular}{ll}
\hline Engine type & Lister-Petter $4 \times 90$, direct-injection, four-stroke, naturally aspirated diesel \\
Configuration & Vertical in-line four-cylinder \\
Cylinder bore, stroke & $90 \mathrm{~mm}, 90 \mathrm{~mm}$ \\
Connecting rod length & $138 \mathrm{~mm}$ \\
Compression ratio & $18.5: 1$ \\
Total displacement & $2.29 \mathrm{l}$ \\
Rated speed & $1800 \mathrm{r} / \mathrm{min}$ \\
Rated power & $37.5 \mathrm{~kW}$ at $2100 \mathrm{r} / \mathrm{min}$ \\
Fuel injection pump & Lucas rotary \\
\hline
\end{tabular}

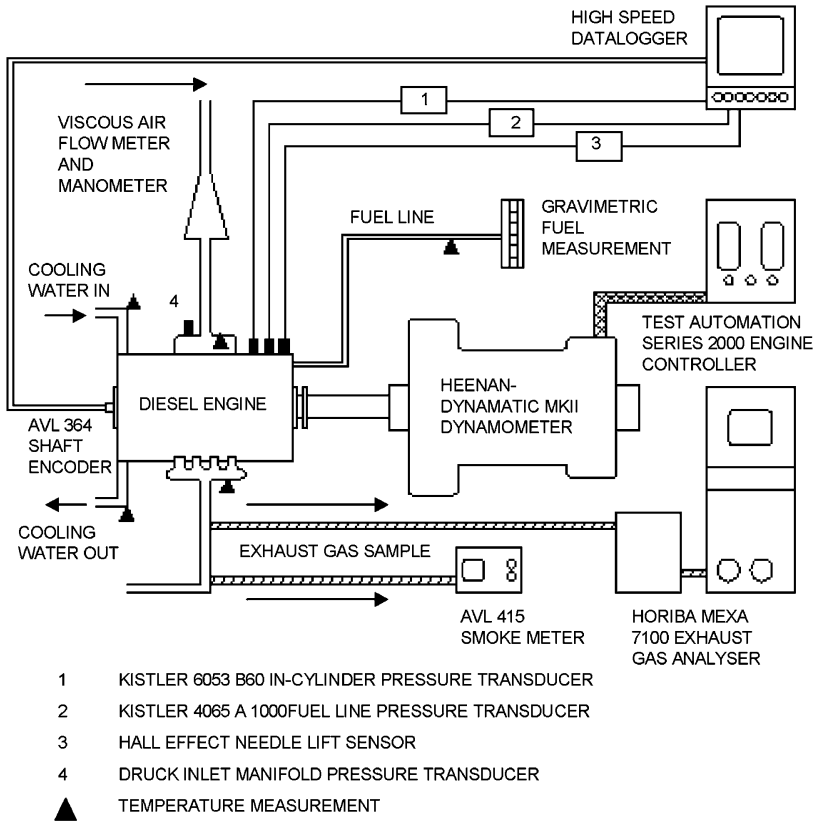

a

\section{Schematic diagram of the engine and equipment}

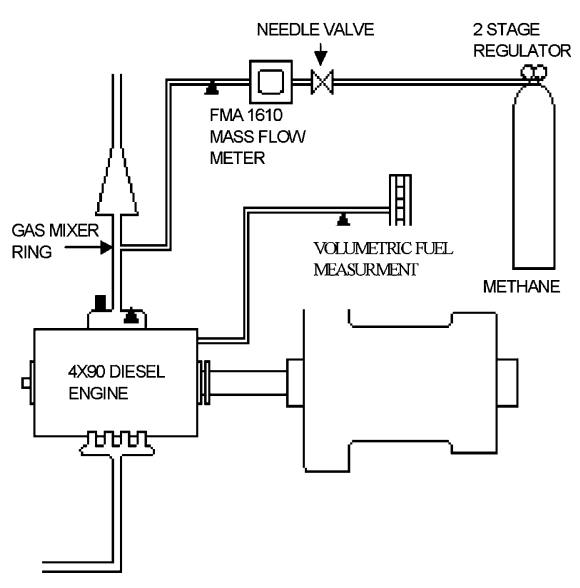

b

Schematic of gas installation

Fig. 1 Schematic diagram of the test engine and dual-fuel conversion

were recorded with a resolution of $0.5^{\circ} \mathrm{CA}$ on the falling edge of the signal from an AVL optical encoder, mounted directly on the engine crankshaft. The encoder also supplied a single pulse per revolution signal to mark top dead centre and triggered data acquisition of 50 consecutive four-stroke cycles for analysis.

\subsection{Dual-fuel conversion}

Turner and Weaver [17] concluded that a simple central point mixing system is the most inexpensive and straightforward method of admitting a gaseous fuel to the dual-fuel engine. To this end, a simple venturi-type gas mixer valve was installed at a distance of ten pipe diameters upstream of the inlet manifold to ensure complete mixing of the air and fuel was achieved. The gaseous fuel flowrate was controlled by a needle valve located immediately upstream of an Omega FMA 1610 mass flowmeter, which also recorded line pressure and fuel temperature. The details of this gas supply system are shown schematically in Fig. 1(b). The only other modification made to the engine was the replacement of the standard injectors with reduced flow injectors to improve injection performance.

\subsection{Method}

Engine performance data were obtained under steady state operating conditions at three loads corresponding to quarter-, half-, and three-quarters-load (relative to 100 per cent load being $18.7 \mathrm{~kW}$ ), at an engine speed of $1500 \mathrm{r} / \mathrm{min}$. This speed was used as the original test programme was centred on electrical power production. 
To ensure consistent operating conditions, the engine was run for approximately $10 \mathrm{~min}$ at 1500 $\mathrm{r} / \mathrm{min}$ and half-load until the cooling water temperature out of the cylinder head reached $80^{\circ} \mathrm{C}$, and the exhaust gas temperature reached $250{ }^{\circ} \mathrm{C}$. The engine was then brought to the required test point and allowed to settle before sampling of data began.

The first and last set of data to be acquired were for standard No. 2 diesel. The first data set served as a baseline with which subsequent results could be compared, and the last data set confirmed that the results were repeatable and that the engine performance had not been impaired by the use of gaseous fuels. Selected key properties for the diesel and gaseous fuels are presented in Table $2[\mathbf{1 8}, \mathbf{1 9}]$.

\section{HEAT RELEASE RATE MODELLING AND ANALYSIS}

Heat release analysis of in-cylinder pressure data is a widely used combustion diagnostic tool and reveals information regarding the rate processes and combustion characteristics occurring inside the engine. In itself, the heat release rate is strongly related to emissions characteristics, which provides some information about the combustion process [20]. However, information about the time development of thermodynamic variables is also required.

The heat release analysis used here (based on reference [21]) consists of three control volumes; this is conceptually closer to dual-fuel combustion where diesel is injected into an unburned zone (air and a gaseous fuel) and eventually a burned zone is formed. This approach was also chosen because it allows a model for fuel injection to be derived from actual operating conditions. Figure 2 shows the three zones contained within the combustion chamber used for the subsequent analysis.

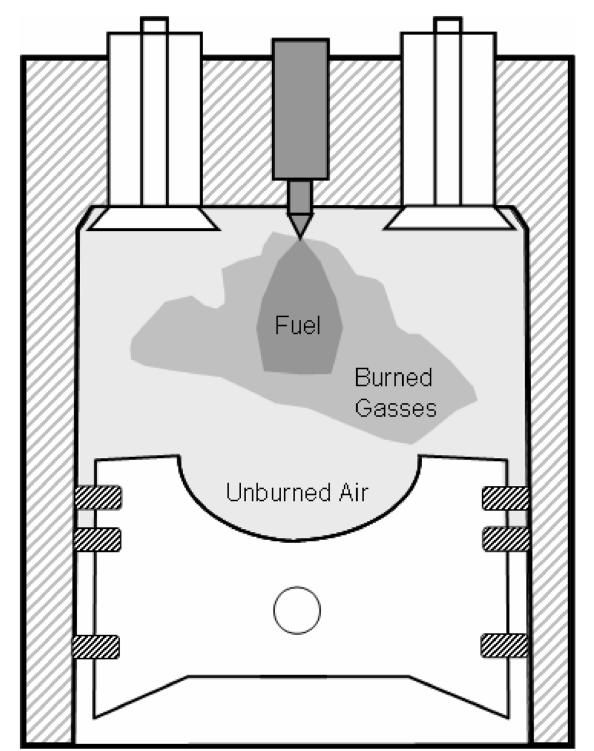

Fig. 2 Schematic diagram of the three-zone model

The assumptions made are as follows.

1. The combustion chamber consists of a diesel fuel zone, an unburned zone, and a burned zone (denoted by the subscripts $\mathrm{f}, \mathrm{u}$, and $\mathrm{b}$ respectively). Each zone has uniform temperature and composition, and the pressure is uniform across the whole combustion chamber.

2. The diesel fuel zone refers only to the diesel pilot which upon injection is assumed to vaporize instantly.

3. The unburned zone into which fuel is injected is assumed to consist of air, exhaust gas residuals, and gaseous fuel in their measured proportions.

4. The burned zone appears when combustion begins and is subsequently confirmed by finding the point at which the first derivative of pressure with respect to time reaches a minimum value [22].

Table 2 Selected properties of the gaseous fuels (properties of diesel from Esso ultra-low sulphur diesel from Esso marketing technical bulletin [19]; properties of gaseous fuels from manufacturers' data sheets [18])

\begin{tabular}{lllll}
\hline & \multicolumn{3}{c}{ Value for the following fuels } \\
\cline { 2 - 5 } Parameter (units) & Methane & Propane & Butane & Diesel \\
\hline Chemical formula & $\mathrm{CH}_{4}$ & $\mathrm{C}_{3} \mathrm{H}_{8}$ & $\mathrm{C}_{4} \mathrm{H}_{10}$ & $\approx \mathrm{C}_{12} \mathrm{H}_{26}$ \\
Molecular weight & 16 & 44 & 58 & $\approx 170$ \\
Density at standard temperature and pressure $\left(\mathrm{kg} / \mathrm{m}^{3}\right)$ & 0.647 & 1.779 & 2.345 & $\approx 840$ \\
Lower heating value (MJ/kg) & 50.05 & 46.33 & 45.73 & 42.9 \\
Stoichiometric air-to-fuel ratio & 17.2 & 15.7 & 15.5 & 14.5 \\
Cetane number & $\approx 0$ & $\approx 0$ & $\approx 5$ & $40-55$ \\
Flammability limits vol.\% of gas in air) & & & & \\
$\quad$ Upper & 15.0 & 9.5 & 8.5 & 7.5 \\
Lower & 5.0 & 2.2 & 1.5 & 0.6 \\
\hline
\end{tabular}


5. Combustion is assumed to occur owing to the entrainment of the pilot fuel and unburned gases and subsequent reactions in stoichiometric proportions.

6. Individual species of the burned, unburned, and vaporized fuel can be modelled as ideal gases.

The total mass $m$ in the combustion chamber consists of the mass $m_{\mathrm{o}}$ of the trapped air, which in turn consists of the mass $m_{\mathrm{a}}$ of the air and residual exhaust gases and, in the dual-fuel case, the mass $m_{\mathrm{g}}$ of the gaseous fuel. The charge air and gaseous fuel proportions are determined from measured mass flowrates, and the residual gas fraction is assigned an arbitrary value [21] (as the gas exchange process is not simulated). After the start of fuel injection, the mass of the cylinder also includes the mass of the fuel injected. Therefore the conservation of mass in the cylinder at any instant can be expressed as

$$
m=m_{\mathrm{u}}+m_{\mathrm{b}}+m_{\mathrm{f}}
$$

where

$$
m=m_{\mathrm{o}}+m_{\mathrm{fi}}
$$

and

$$
m_{\mathrm{o}}=m_{\mathrm{a}}+m_{\mathrm{g}}
$$

The rate at which the fuel zone and the unburned zones react to form the burned zone can be calculated by the difference between the mass $m_{\mathrm{fi}}$ of fuel injected at any instant and the current mass $m_{\mathrm{f}}$ in the fuel zone $[\mathbf{2 1}, \mathbf{2 3}]$. For the dual-fuel case there is the added complexity that the mass of the burned zone will also be a function of the mass of gaseous fuel that has been burned during each time step. In order to express this, it is assumed that combustion occurs at a stoichiometric air-to-fuel ratio $\left(\mathrm{AFR}_{\mathrm{s}, \mathrm{tot}}\right)$ $[3,24,25]$. The $A_{F} R_{s, t o t}$ has two hydrocarbon fuel components with molecular formulae of $\mathrm{C}_{x_{\mathrm{d}}} \mathrm{H}_{y_{\mathrm{d}}}$ and $\mathrm{C}_{x_{\mathrm{g}}} \mathrm{H}_{y_{\mathrm{g}}}$, and the mass ratio of the two fuels is also known [26]. Thus, the dual-fuel $\mathrm{AFR}_{\mathrm{s}, \text { tot }}$ is calculated as

$$
\begin{aligned}
& \text { AFR }_{\mathrm{s}, \text { tot }} \\
& \quad=\frac{\left[\alpha\left(x_{\mathrm{d}}+y_{\mathrm{d}} / 4\right)+\beta\left(x_{\mathrm{g}}+y_{\mathrm{g}} / 4\right) \mathrm{MW}_{\mathrm{air}}\right.}{\alpha\left(x_{\mathrm{d}} \mathrm{MW}_{\mathrm{C}}+y_{\mathrm{d}} \mathrm{MW}_{\mathrm{H}}\right)+\beta\left(x_{\mathrm{g}} \mathrm{MW}_{\mathrm{C}}+y_{\mathrm{g}} \mathrm{MW}_{\mathrm{H}}\right)}
\end{aligned}
$$

where

$$
\alpha=\frac{m_{\mathrm{d}}}{m_{\mathrm{d}}+m_{\mathrm{g}}}, \quad \beta=\frac{m_{\mathrm{g}}}{m_{\mathrm{d}}+m_{\mathrm{g}}}
$$

The mass of fuel burned is solved as part of the final equation set. If the overall dual-fuel $\mathrm{AFR}_{\mathrm{s}, \text { tot }}$ is maintained, then the mass of air entrained into the burned zone is given by

$$
\begin{aligned}
m_{\mathrm{b}}= & \left(m_{\mathrm{fi}}-m_{\mathrm{f}}\right)\left(1+\operatorname{AFR}_{\mathrm{s}, \mathrm{tot}}\right) \\
& +\left(m_{\mathrm{fi}}-m_{\mathrm{f}}\right) \frac{\beta}{\alpha}\left(1+\operatorname{AFR}_{\mathrm{s}, \mathrm{tot}}\right)
\end{aligned}
$$

The conservation of mass, the ideal gas law, and the first law of thermodynamics [23] are applied to each zone so that, at any instant, there are 12 unknowns to be solved; the three masses $\left(m_{\mathrm{u}}, m_{\mathrm{f}}\right.$, and $\left.m_{\mathrm{b}}\right)$, the three volumes $\left(V_{\mathrm{u}}, V_{\mathrm{f}}\right.$, and $\left.V_{\mathrm{b}}\right)$, the three temperatures $\left(T_{\mathrm{u}}, T_{\mathrm{f}}\right.$, and $\left.T_{\mathrm{b}}\right)$, and the three internal energies $\left(u_{\mathrm{u}}, u_{\mathrm{f}}\right.$, and $\left.u_{\mathrm{b}}\right)$. However, the system can be reduced to two ordinary differential equations and three algebraic equations. The two ordinary differential equations are

$$
\begin{aligned}
& \frac{\mathrm{d} T_{\mathrm{u}}}{\mathrm{d} \theta}=\frac{\mathrm{d} p}{\mathrm{~d} \theta} \frac{R_{\mathrm{u}} T_{\mathrm{u}}}{p c_{\mathrm{pu}}}+\frac{\mathrm{d} Q_{\mathrm{u}}}{m_{\mathrm{u}} c_{\mathrm{pu}}} \\
& \frac{\mathrm{d} T_{\mathrm{f}}}{\mathrm{d} \theta}=\frac{\mathrm{d} p}{\mathrm{~d} \theta} \frac{R_{\mathrm{f}} T_{\mathrm{f}}}{p c_{\mathrm{pf}}}+\frac{\left(\mathrm{d} m_{\mathrm{f}} / \mathrm{d} \theta\right) \frac{1}{2} V_{\mathrm{inf}}^{2}+\mathrm{d} Q_{\mathrm{f}} / \mathrm{d} \theta}{m_{\mathrm{f}} c_{\mathrm{pf}}}
\end{aligned}
$$

the unknowns $T_{\mathrm{u}}$ and $T_{\mathrm{f}}$ are solved by the fourthorder Runge-Kutta method. Once $T_{\mathrm{u}}$ and $T_{\mathrm{f}}$ are known, $m_{\mathrm{u}}, m_{\mathrm{f}}$, and $T_{\mathrm{b}}$ are found from the three algebraic equations

$$
\begin{aligned}
& f_{1}\left(m_{\mathrm{u}}, m_{\mathrm{f}}, T_{\mathrm{b}}\right)=m_{\mathrm{u}}+m_{\mathrm{f}}+\left(m_{\mathrm{fi}}-m_{\mathrm{f}}\right)\left(1+\mathrm{AFR}_{\mathrm{s}, \mathrm{tot}}\right) \\
& +\left(m_{\mathrm{g}}-m_{\mathrm{u}} \beta\right)\left(1+\mathrm{AFR}_{\mathrm{s}, \mathrm{tot}}\right)-m \\
& =0 \\
& f_{2}\left(m_{\mathrm{u}}, m_{\mathrm{f}}, T_{\mathrm{b}}\right) \\
& =m_{\mathrm{u}} R_{\mathrm{u}} T_{\mathrm{u}}+m_{\mathrm{f}} R_{\mathrm{f}} T_{\mathrm{f}} \\
& \times\left[\left(m_{\mathrm{fi}}-m_{\mathrm{f}}\right)\left(1+\mathrm{AFR}_{\mathrm{s}, \mathrm{tot}}\right)\right. \\
& \left.+\left(m_{\mathrm{g}}-m_{\mathrm{u}} \beta\right)\left(1+\mathrm{AFR}_{\mathrm{s}, \text { tot }}\right)\right] R_{\mathrm{b}} T_{\mathrm{b}}-p V \\
& =0
\end{aligned}
$$

$$
\begin{aligned}
f_{3}\left(m_{\mathrm{u}}, m_{\mathrm{f}}, T_{\mathrm{b}}\right)= & m_{\mathrm{u}} u_{\mathrm{u}}+m_{\mathrm{f}} u_{\mathrm{f}}+R_{\mathrm{b}} u_{\mathrm{b}} \\
& \times\left[\left(m_{\mathrm{fi}}-m_{\mathrm{f}}\right)\left(1+\mathrm{AFR}_{\mathrm{s}, \text { tot }}\right)\right. \\
& \left.\quad+\left(m_{\mathrm{g}}-\beta m_{\mathrm{u}}\right)\left(1+\mathrm{AFR}_{\mathrm{s}, \mathrm{tot}}\right)\right] \\
& \quad-U_{0}-Q_{\mathrm{T}}-m_{\mathrm{fi}}\left(h_{\mathrm{f}}+\frac{1}{2} V_{\mathrm{inj}}^{2}\right)+W \\
= & 0
\end{aligned}
$$

which are solved by the Newton-Rhapson technique [27]. The main inputs to the model are a record of the cylinder pressure $p$ against CA $\theta$, data for the diesel fuel mass flowrate, needle lift, and fuel line 
pressure to determine the mass flowrate and injection velocity of the pilot fuel. Other inputs required are the inlet temperatures and mass flowrates of the gaseous fuel and air, from which initial conditions at inlet valve closure and the mass fractions of gaseous fuel and air can be calculated.

At the start of injection (SOI) the fuel zone comes into existence and, during the short ignition delay period, the values of temperature, heat transfer $d Q_{u}$ and $\mathrm{d} Q_{\mathrm{f}}$, and internal energy are calculated. The burned zone then appears at the start of combustion (SOC), and equations (5) to (9) are solved. A record of the burned zone composition is preserved and used to calculate the new thermodynamic properties [28]. A flow chart description of the three-zone model is provided in Fig. 3.

\section{RESULTS AND DISCUSSION}

This section presents the experimental data and results for the combustion phasing characteristics and energy utilization of the engine using three different primary fuel gases, and the heat release rate data obtained from the three-zone heat release model. For this discussion section the primary fuel refers to the ingested gaseous fuel and air mixture.

Table 3 supplies details of the split between the energy supplied from the gaseous and diesel fuels.

\subsection{Combustion phasing}

Combustion phasing data for the three fuels under a fixed engine speed $(1500 \mathrm{r} / \mathrm{min})$ for various loads are presented in Table 4 . Although the rated speed for this engine was $1800 \mathrm{r} / \mathrm{min}$, the speed examined was $1500 \mathrm{r} / \mathrm{min}$ as the test programme was originally based on a generator set operating at a frequency of $50 \mathrm{~Hz}$. Although this was not the rated engine speed, the trends for rated speed should replicate those presented within this paper.

The results contained within Table 4 show that, as the primary air-to-fuel ratio is increased, the location of peak pressure occurs later in the cycle and the ignition delay period increases. However, as the load increases, the delay between SOC and SOI improves. It also reveals that, as the engine load is increased, the combustion duration is approximately constant, but the ignition delay period reduces very slightly.

For quarter-load it was noticed that, as the percentage of primary fuel was increased, there was an increase in the variability of the position of the location of the peak pressure. This would imply that the cyclic variability of the engine had increased.

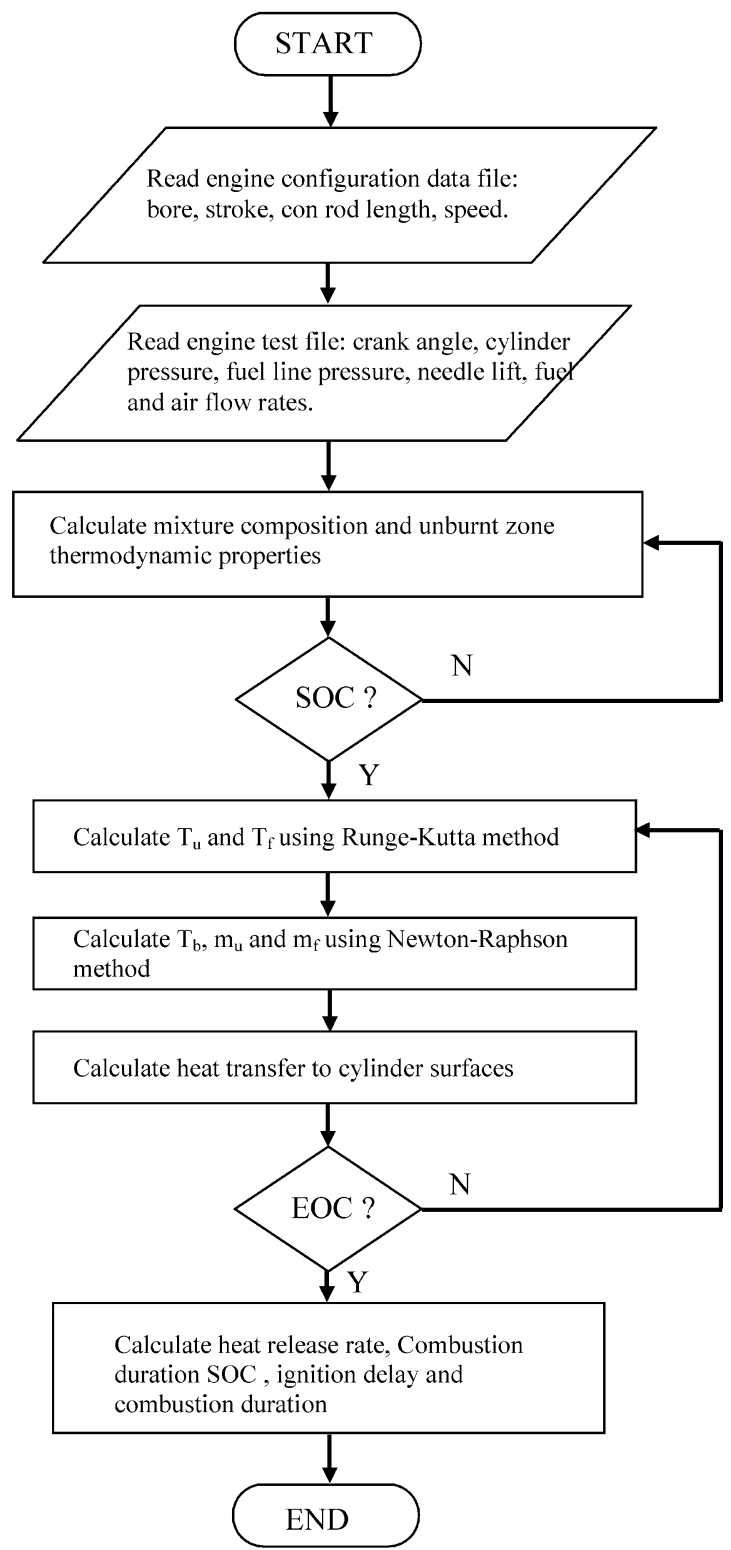

Fig. 3 Flow chart for three-zone computer program

Across the load range, the maximum 'variability' was found with butane as the primary fuel; this was attributed to the relatively small quantities of liquid (diesel) fuel being injected as the injection timings were held nearly constant for a given load condition. Using propane as the primary fuel caused an extended ignition delay. However, because propane is a more reactive hydrocarbon, this delay was offset by the rapid premixed combustion processes.

\subsection{Results of three-zone heat release analysis}

A number of test cases are now examined using the three-zone combustion model, presented in section 3 , for determination of the rate of heat release. 
Table 3 Comparison of fuelling conditions

\begin{tabular}{|c|c|c|}
\hline Primary $\Phi$ & $\begin{array}{l}\text { Energy supplied by } \\
\text { primary }(\%)\end{array}$ & $\begin{array}{l}\text { Energy supplied by } \\
\text { pilot }(\%)\end{array}$ \\
\hline \multicolumn{3}{|c|}{ Methane, quarter-load } \\
\hline 0.02 & 9.76 & 90.24 \\
\hline 0.12 & 43.98 & 56.02 \\
\hline 0.29 & 65.42 & 34.58 \\
\hline \multicolumn{3}{|c|}{ Propane, quarter-load } \\
\hline 0.01 & 6.36 & 93.64 \\
\hline 0.03 & 16.31 & 83.69 \\
\hline 0.11 & 49.84 & 50.16 \\
\hline \multicolumn{3}{|c|}{ Butane, quarter-load } \\
\hline 0.02 & 10.30 & 89.70 \\
\hline 0.03 & 15.93 & 84.07 \\
\hline 0.11 & 42.92 & 57.08 \\
\hline \multicolumn{3}{|c|}{ Methane, half-load } \\
\hline 0.03 & 9.68 & 90.32 \\
\hline 0.18 & 45.86 & 54.14 \\
\hline 0.33 & 71.06 & 28.94 \\
\hline \multicolumn{3}{|c|}{ Propane, half-load } \\
\hline 0.01 & 3.99 & 96.01 \\
\hline 0.16 & 58.83 & 41.17 \\
\hline \multicolumn{3}{|c|}{ Butane, half-load } \\
\hline 0.03 & 9.72 & 90.28 \\
\hline 0.16 & 43.91 & 56.09 \\
\hline \multicolumn{3}{|c|}{ Methane, three-quarters-load } \\
\hline 0.05 & 10.47 & 89.53 \\
\hline 0.13 & 26.08 & 73.92 \\
\hline 0.70 & 82.01 & 17.99 \\
\hline \multicolumn{3}{|c|}{ Propane, three-quarters-load } \\
\hline 0.03 & 6.42 & 93.58 \\
\hline 0.15 & 40.83 & 59.17 \\
\hline 0.23 & 66.84 & 59.17 \\
\hline \multicolumn{3}{|c|}{ Butane, three-quarters-load } \\
\hline 0.05 & 10.82 & 89.18 \\
\hline 0.12 & 26.47 & 73.53 \\
\hline 0.20 & 43.47 & 56.53 \\
\hline \multicolumn{3}{|c|}{ Methane, full load } \\
\hline 0.06 & 9.5 & 90.5 \\
\hline 0.17 & 25.0 & 75.0 \\
\hline 0.55 & 80.7 & 19.3 \\
\hline
\end{tabular}

\subsubsection{Full-load condition with methane gas substitution}

Cylinder pressure data against CA for the full-load case using diesel and diesel-methane fuelling are plotted for a range of primary equivalence ratios in Fig. 4 . As the primary fuel-to-air equivalence ratio is increased, the compression pressures are reduced. This is due to the reduction in the ratio of specific heat capacities of the ingested mixture. These reduced cylinder pressures, at SOI, imply lower corresponding cylinder temperatures; which increases the ignition delays of the injected fuel-gas mixture.

As the percentage of energy supplied by the premixed charge increases, the combustion duration increases. For the case when $\Phi=0.55$ the initial rate of pressure rise is reduced and the position of the maximum pressure is shifted to the right consider- ably. Although the area under the rate of heat release curve for the case when $\Phi=0.55$ is significantly larger than the other cases, no increase in engine power (torque) was recorded.

\subsubsection{Load changes with different fuels}

Figures 6, 7, and 8 show the rate of heat release against CA for a range of primary fuel equivalence ratios for the three fuels, methane, propane, and butane respectively at a fixed engine speed $(1500 \mathrm{r} / \mathrm{min})$. For each case the primary air-to-fuel ratio (equivalence ratio) was held constant. For these test cases the injection timing was held approximately constant $\left(10^{\circ}\right.$ before top dead centre $\left.\pm 2.5^{\circ} \mathrm{CA}\right)$.

When using methane as the primary fuel, higher energy substitution levels were obtained than for the other two primary fuels. The highest heat release rates (and peak pressures) obtained were recorded with methane, as were the most stable combustion processes based on simple combustion diagnostics.

Figure 6 shows a full-load swing using methane as the primary fuel. It should be noted that, as the load was increased, more of the cycle energy was supplied from the diesel fuel. This implies a larger pilot injection mass which tends to promote a more stable and 'smoother' combustion process.

Heat release rate data for propane and butane are presented in Figs 7 and 8 respectively. These primary fuels exhibited decreasing and then increasing peak rates of heat release (peak cylinder pressures) that occur later in the cycle. This indicates that some change to the basic combustion processes has occurred.

For all data sets examined, propane produced an extended ignition delay compared with either methane or butane. It has been previously noted that the addition of propane has a deleterious effect on the pre-ignition processes leading to delayed SOC and initially slower rates of mass burning [15].

However, propane is considered to be a fastreacting fuel and, in spite of the delayed SOC, the mass burning rates subsequently are increased and the overall rate of heat release exceed those of butane but do not quite catch up with those of methane. It can be concluded that, at low loads, a more reactive primary fuel will result in a delayed combustion process through its competition for pre-ignition reaction radicals.

Butane's competition with the diesel pilot for active radicals [15] leads to reduced (but not delayed) initial rates of heat release and a less positive, less rapid, and less wide-reaching ignition process. At the same time, butane requires a greater quantity of oxygen 
Table 4 Comparison of combustion phasing parameters

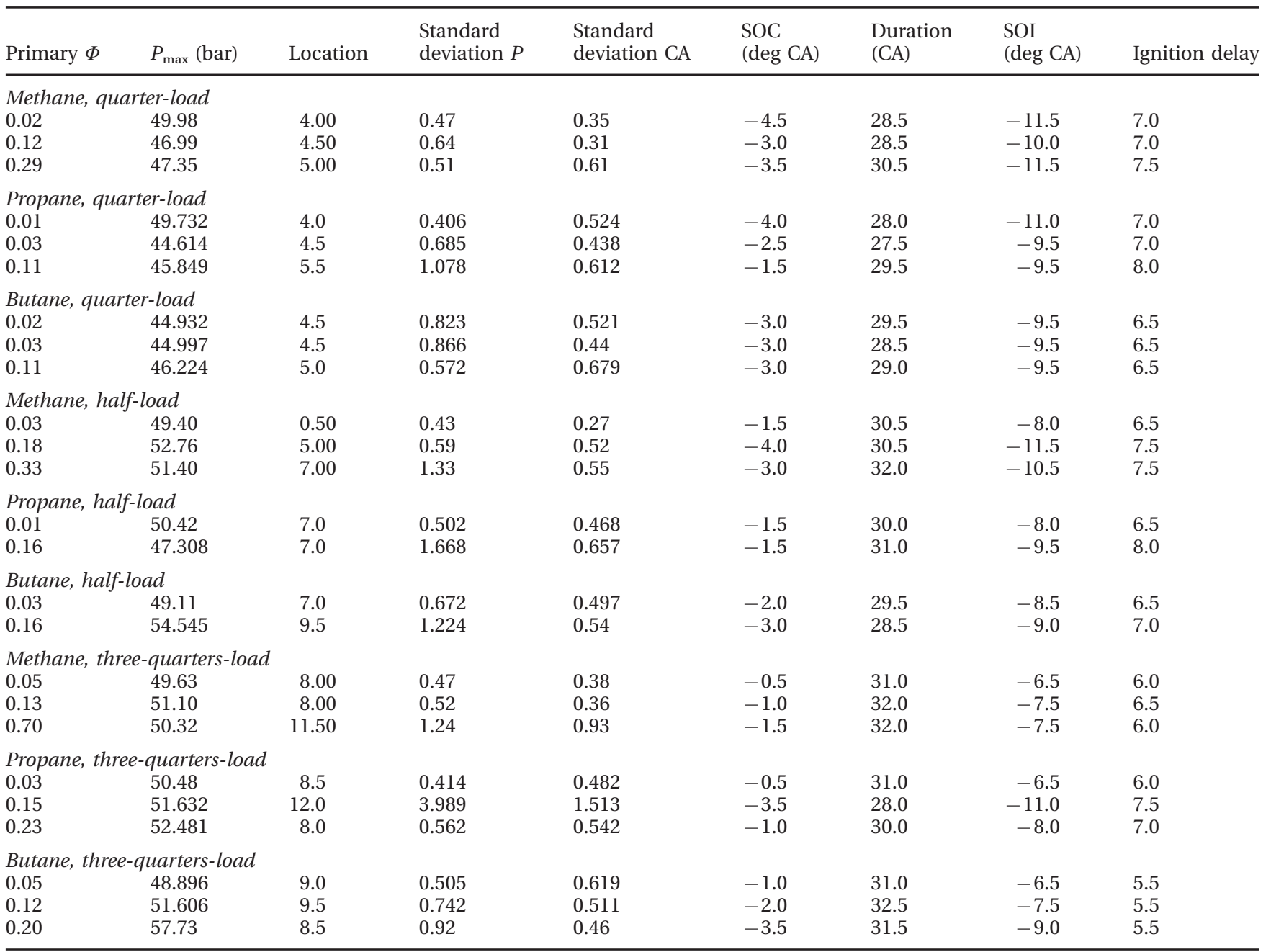

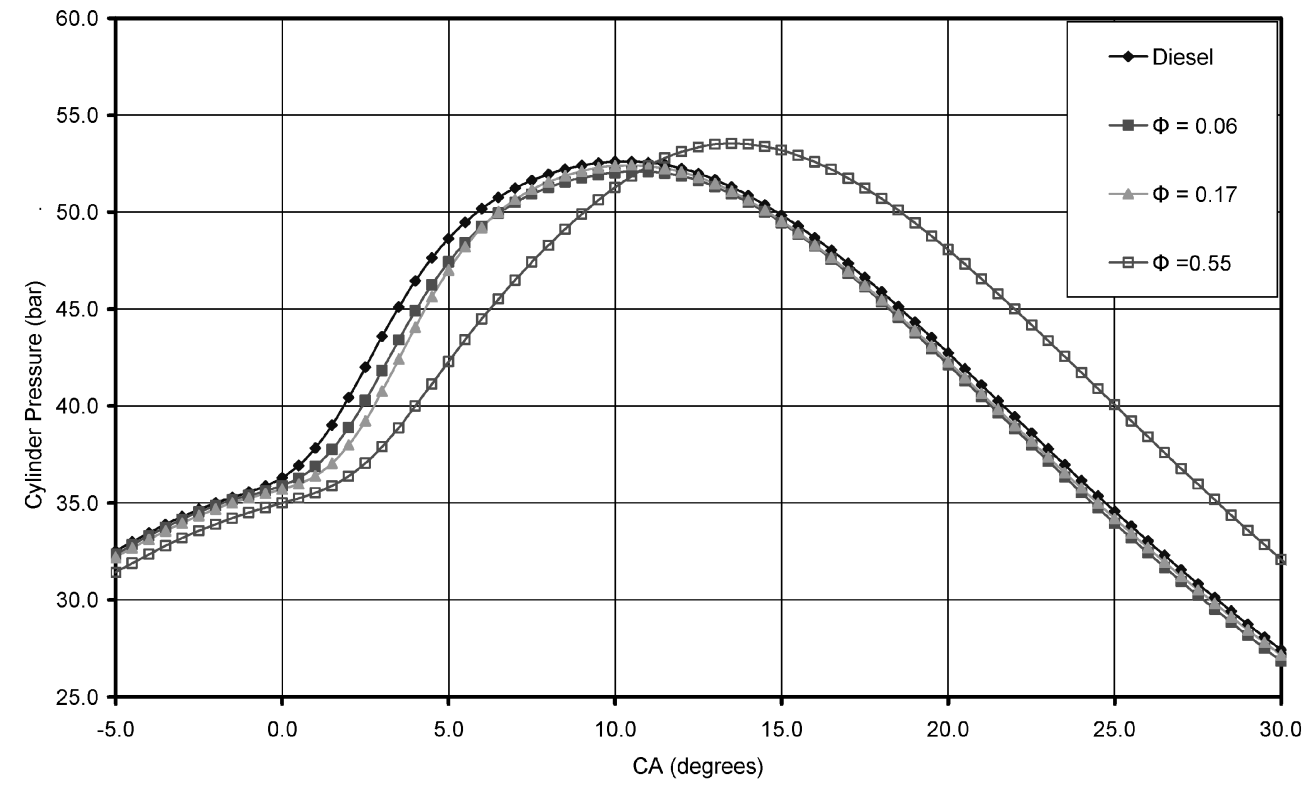

Fig. 4 Experimental cylinder pressure versus CA for diesel and methane-diesel at full load and $1500 \mathrm{r} / \mathrm{min}$ 


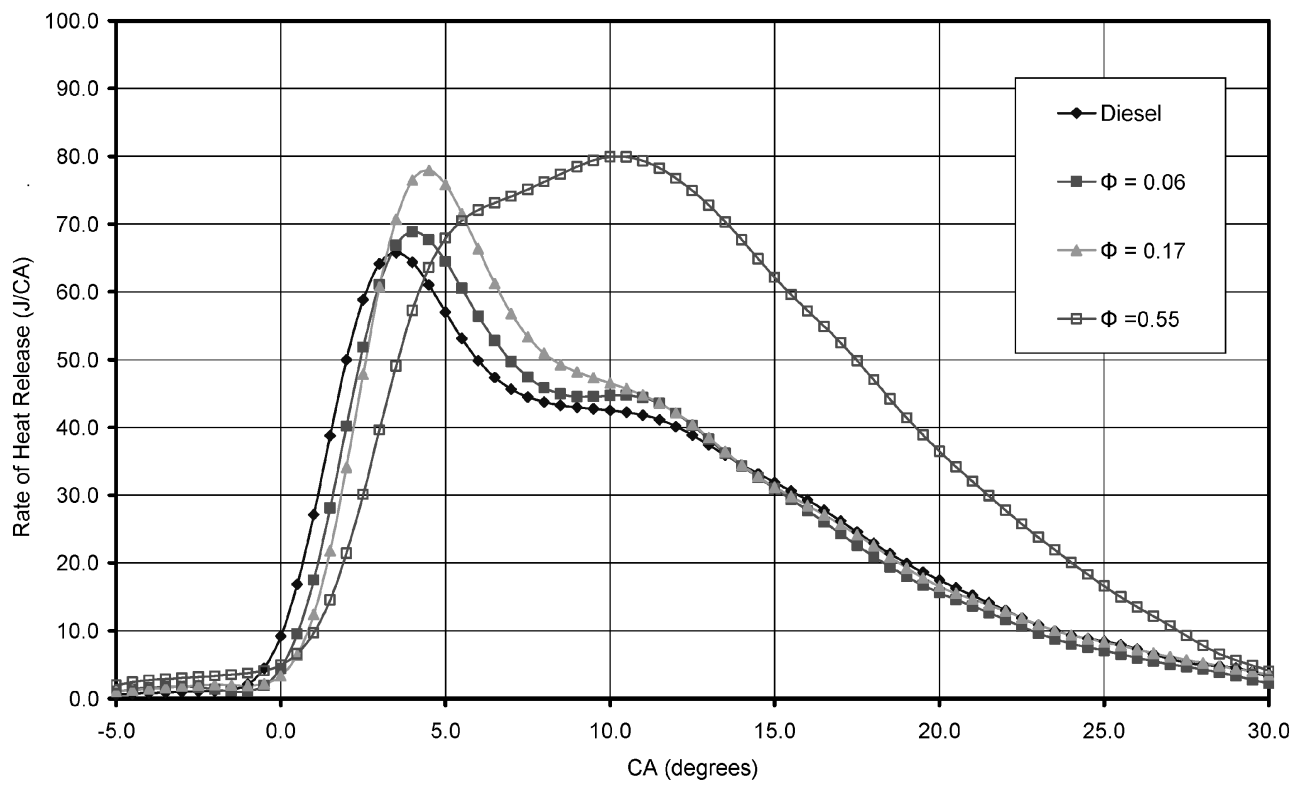

Fig. 5 Calculated heat release rate versus CA for diesel and methane-diesel at full load and $1500 \mathrm{r} / \mathrm{min}$

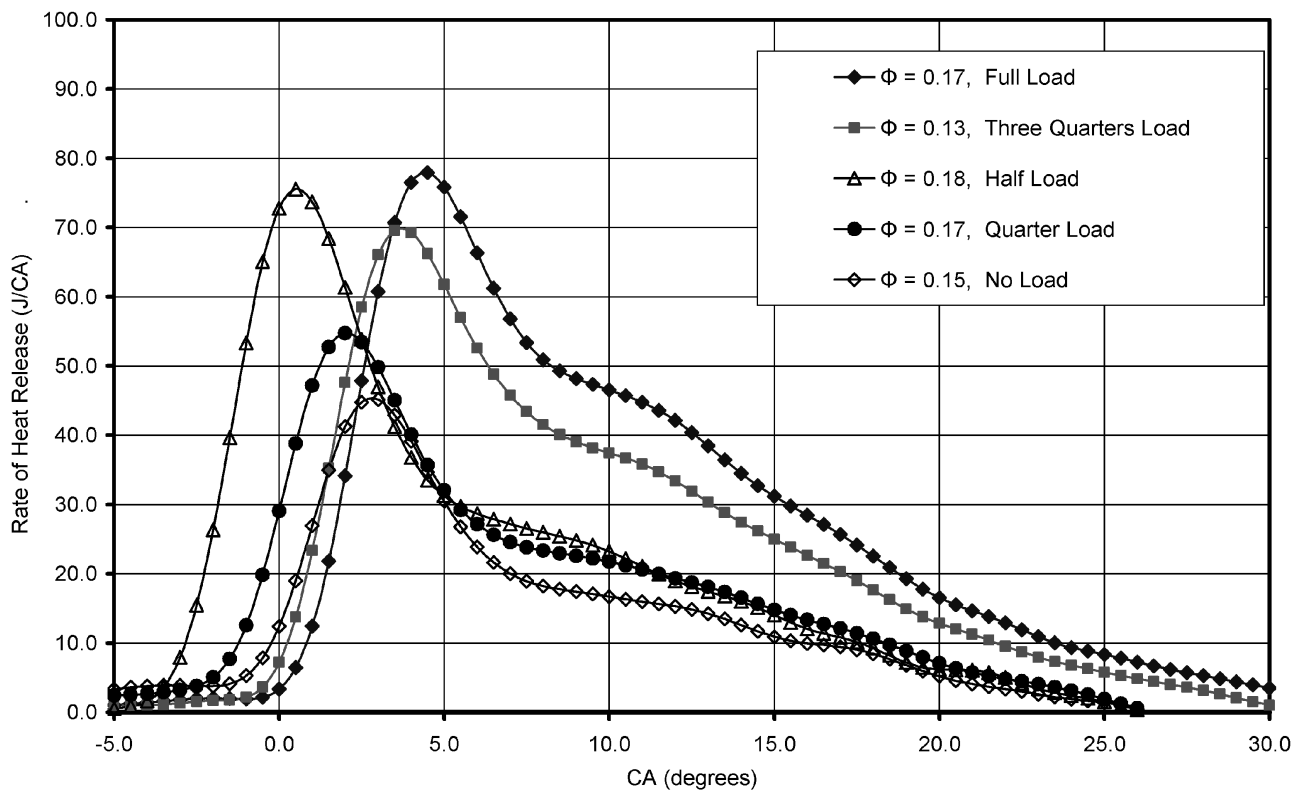

Fig. 6 Calculated heat release rate versus CA for diesel and methane-diesel for different loads at $1500 \mathrm{r} / \mathrm{min}$

than propane does for complete combustion (molar based). Therefore, local conditions in the reaction zone were fuel rich, and overall the combustion process was less complete.

As the primary fuel changes from methane to butane, it can be seen that the diffusion section of the combustion process becomes more important, i.e. a larger proportion of the energy being released is occurring in the 'diffusion' stage. This shows that the premixed charge is taking a more important role in the overall heat release of the fuel inside the engine. It was found experimentally that, at low primary air-to-fuel ratios, the butane-fuelled case had a more pronounced diffusion combustion section (after the initial rapid burning of the diesel).

Considering the combustion processes to proceed in two distinct stages, namely premixed and diffusion, it is revealed that, as the carbon number of the primary fuel is increased, the initial rate of heat release is reduced (a non-linear relationship) and that the 


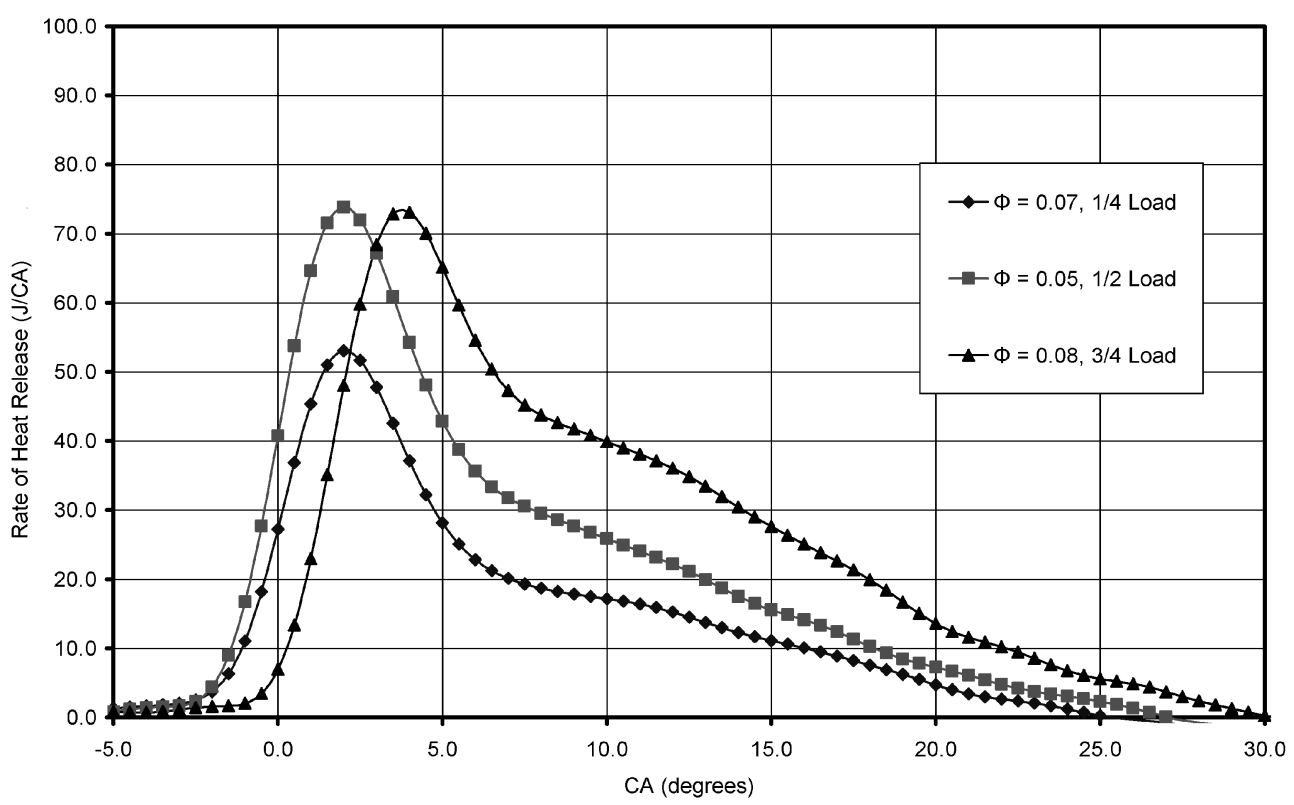

Fig. 7 Calculated heat release rate versus CA for diesel and propane-diesel at different loads and $1500 \mathrm{r} / \mathrm{min}$

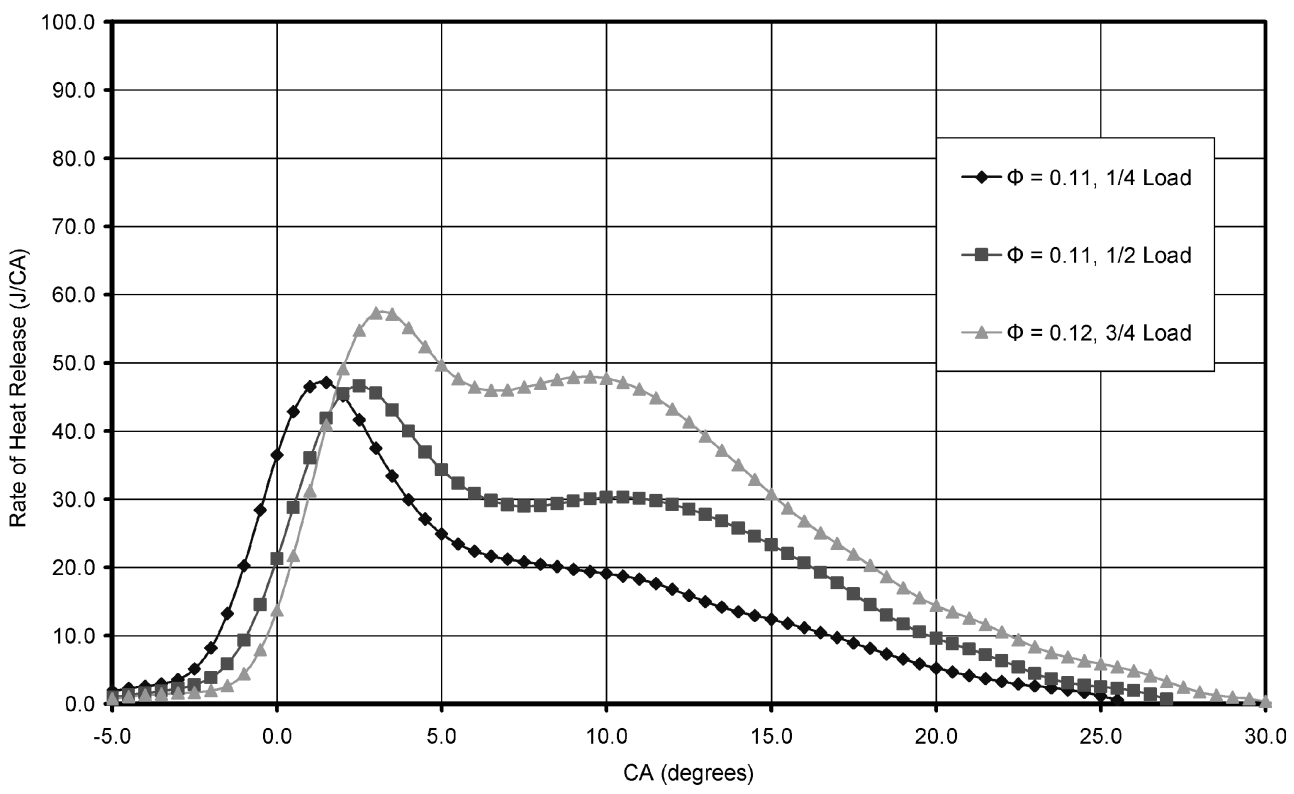

Fig. 8 Calculated heat release rate versus CA for diesel and butane-diesel at full load and $1500 \mathrm{r} / \mathrm{min}$

diffusion stage is increased. This is important as it may place a limit upon the fuel type that is used for primary fuel substitution.

\subsubsection{Effects of engine speed}

Using a fixed primary air-to-fuel ratio $(\Phi=0.32 \pm 0.01)$ with methane as the primary fuel the effects of engine speed on the rate of heat release were examined. For these tests the engine output torque was held constant. Thus the engine power increased as the engine speed was increased.

As a large quantity of the energy available is supplied by the gaseous fuel, it is not surprising to find that, as the engine speed increases, the rate of heat release (and subsequent pressure development) is reduced and the rate of heat release is 'flattened'.

As the engine speed is increased, the trend is that the initial rate of combustion is reduced as a function of engine speed and a greater proportion of the 


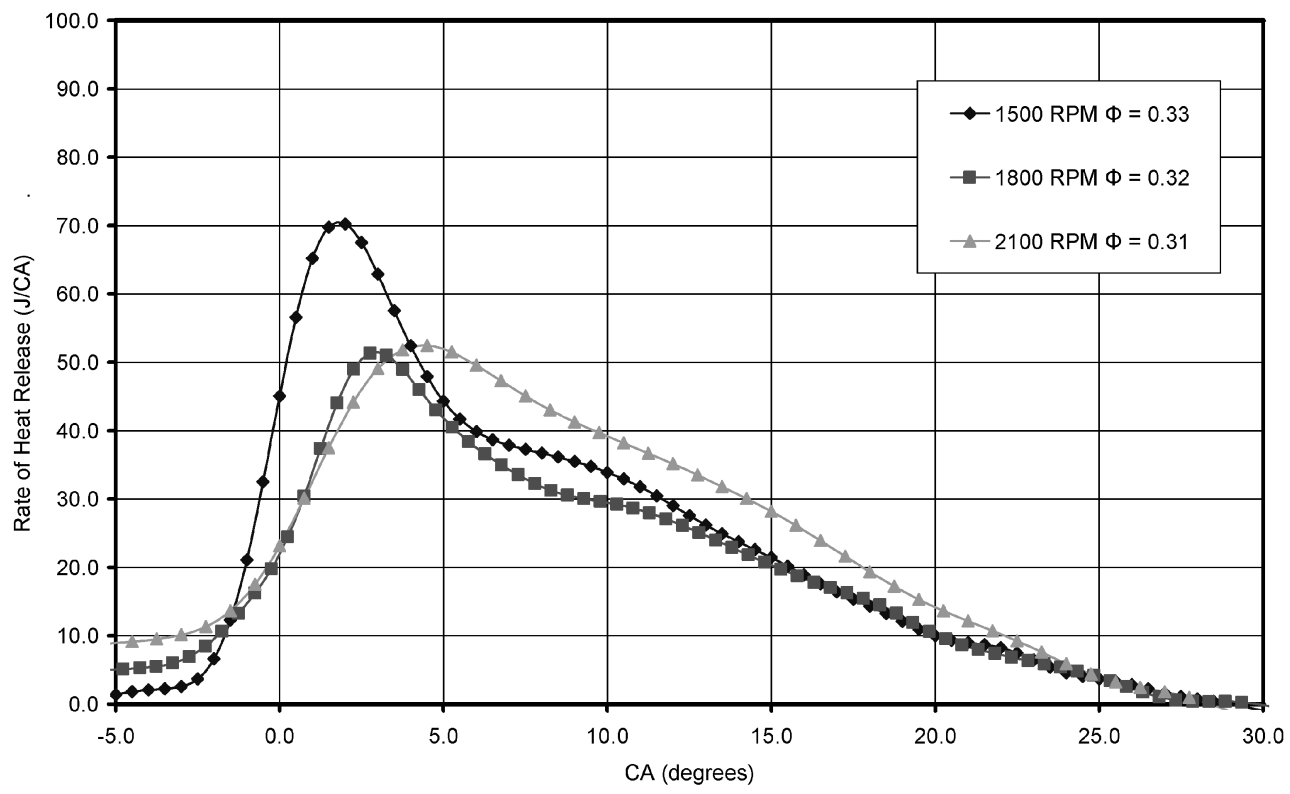

Fig. 9 Calculated heat release rate versus CA for diesel and methane-diesel at half-load (relative to the $1500 \mathrm{r} / \mathrm{min}$ case) and different engine speeds

energy release rate is during the latter stages of combustion. This may be of benefit for noise reduction but may hinder the employment in current high-speed direct-injection engines which require higher rates of combustion for minimization of fuel consumption.

When considering the time base for analysis, the combustion duration is approximately constant for all speed tests considered. This may be a limiting case for the utilization of the dual-fuel concept for automotive application where high engine speeds are required to optimize the powertrain.

\subsection{Brake specific energy consumption}

The brake specific energy consumption (BSEC) is used for this study because of the different fuel types and their combinational and combustion characteristics. This metric allows an understanding of the total fuel energy utilization and conversion.

Data are plotted to compare the three primary fuels in Fig. 10 for the quarter-load case at $1500 \mathrm{r} / \mathrm{min}$. As the equivalence ratio of each gaseous primary fuel was increased, the following were observed. The BSEC increases slightly for the butane cases and

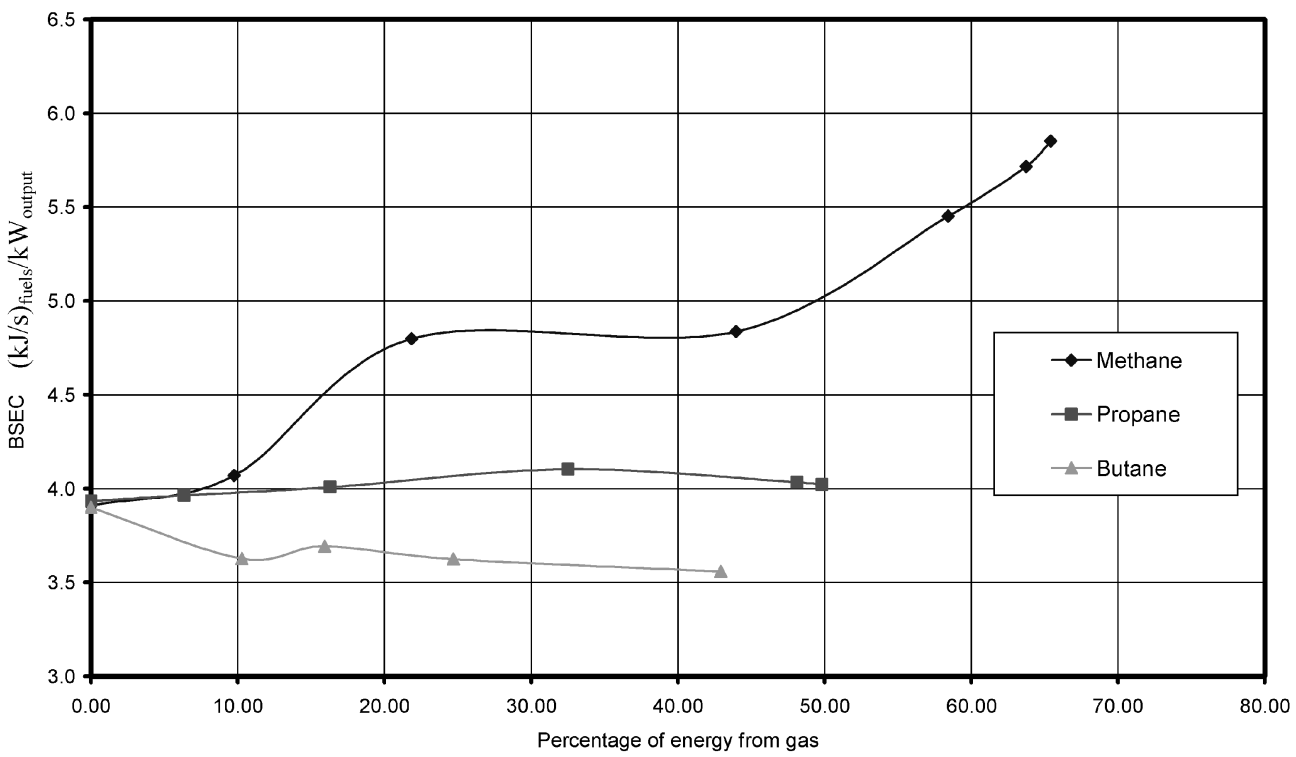

Fig. 10 Comparison of BSEC at quarter-load and $1500 \mathrm{r} / \mathrm{min}$ 
decreases with propane. For the case of methane gas substitution, significant increases in BSEC were observed. It should be noted that a much greater volumetric quantity of methane was used to replace the diesel fuel than was possible to achieve with propane (which exhibited knock at the highest levels) or butane (where the maximum fuel quantity was limited by the minimum pilot level that could be supplied). However, when the results are compared over the same fuelling range (up to $\Phi=0.10$ ), methane still showed the greater increase in BSEC.

Data for the half-load case are plotted in Fig. 11. Methane and butane follow similar trends to the quarter-load case, but the propane data show a considerable reduction in required input energy for a desired energy output (approximately a 20 per cent reduction in required input energy). This is attributed to the more reactive aspects of the fuel and hence to increased combustion completeness.

Figure 12 presents the three-quarters-load case. For this case, the trends observed during the half-load tests were maintained. When methane is employed, the energy conversion is reduced but, at very high levels of energy, substitution appears to reverse. This is currently being investigated further. Again, propane performs best; as for the half-load case it

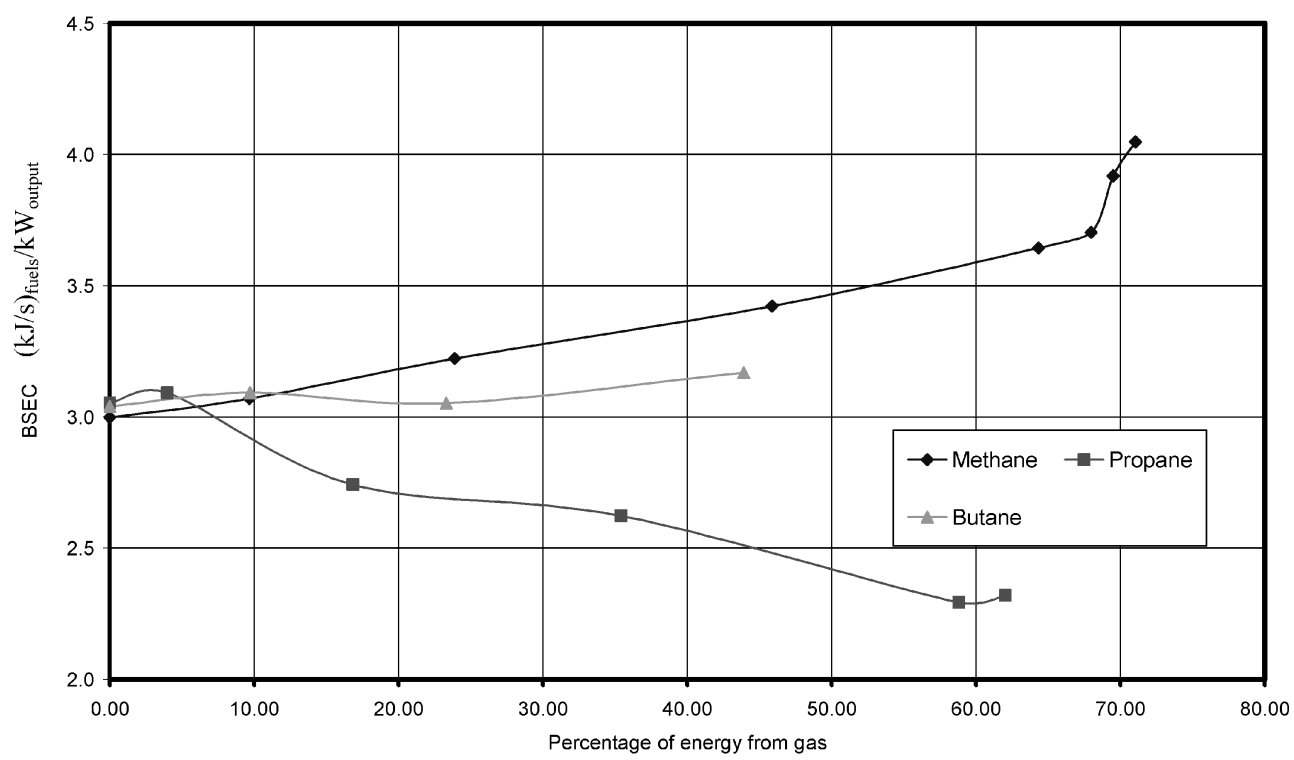

Fig. 11 Comparison of BSEC at half-load and $1500 \mathrm{r} / \mathrm{min}$

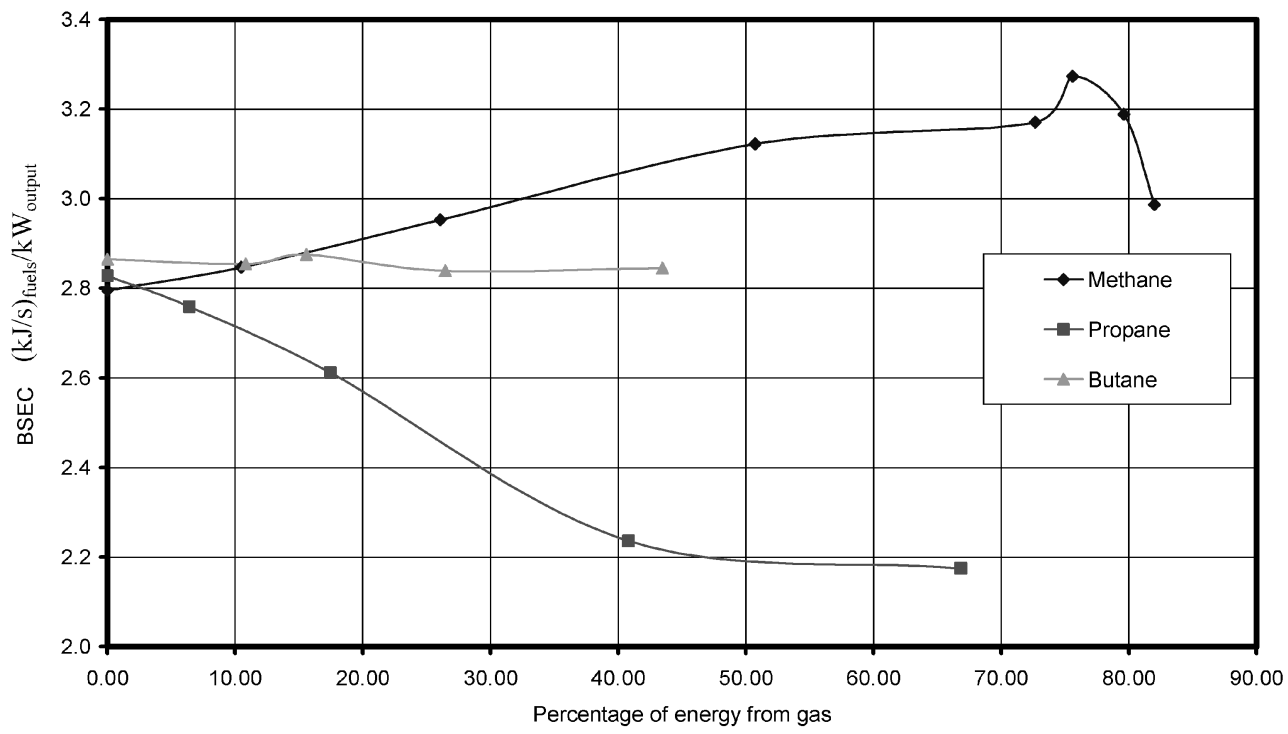

Fig. 12 Comparison of BSEC at three-quarters-load and $1500 \mathrm{r} / \mathrm{min}$ 
appears that the maximum fuel economy is reached with a BSEC of approximately 20 per cent less than for the 100 per cent diesel fuelling case.

\subsection{Carbon dioxide reductions}

If the engineer were only to consider the BSEC plots, a key advantage of the dual-fuel engine may be missed. As these engines use a fuel with a higher carbon-to-hydrogen ratio, they produce lower $\mathrm{CO}_{2}$ emissions per unit volume and energy of fuel used.

Figure 13 is a plot of $\mathrm{CO}_{2}$ reductions for each primary fuel tested as a function of the percentage of energy replaced. For all test cases presented, the $\mathrm{CO}_{2}$ emissions of the engine are reduced significantly. For the case of methane, as the primary fuel for substitution, a 20 per cent reduction of $\mathrm{CO}_{2}$ based on grams per kilowatt hour can be achieved. This clearly demonstrates that, if only specific energy considerations are examined, the benefits of the $\mathrm{CO}_{2}$ reduction of using a fuel with a lower carbonto-hydrogen ratio can be missed. If the engine community is to achieve the required reductions of greenhouse gases, then the 'dual-fuel' engine must be considered.

\section{CONCLUDING SUMMARY}

This paper has investigated three alternative gaseous fuels, based upon CNG and LPG, for use in a compression ignition dual-fuel engine and has applied an advanced three-zone heat release model for analysis purposes. The key findings are as follows.
1. As the percentage of gas substitution is increased, the maximum cylinder pressures occur at a later point within the cycle but are 'slightly' increased in magnitude. Using the three-zone model, the initial rates of heat release are reduced and the diffusion stage of combustion takes on a more significant role as the primary fuel ratio is increased.

2. As the load is increased, it was found that, the higher the carbon content of the fuel, the greater is the importance of the second stage of the combustion process for energy conversion. Butane displayed the widest 'broadening' of the whole combustion process based on heat release analysis.

3 . When the engine speed is increased for a fixed engine torque, the role of diffusional, or turbulent premixed combustion, processes becomes more important. This may be a limiting factor for modern high-speed direct-injection diesel engines.

4. Propane showed the most promising characteristic as a dual-fuel primary fuel. For both half- and three-quarters-load cases a reduction of 20 per cent energy consumption was recorded. This was attributed to the enhanced reactivity of the fuel. Methane, which has been the fuel of choice, was found to increase the BSEC for all cases considered. Maximum gas substitution levels were obtained while using methane; at these very high levels of substitution the BSEC values were found to start to decrease.

5. This engine clearly showed the benefits of reduced $\mathrm{CO}_{2}$ emissions which must be considered if proposed global reductions are to be achieved within

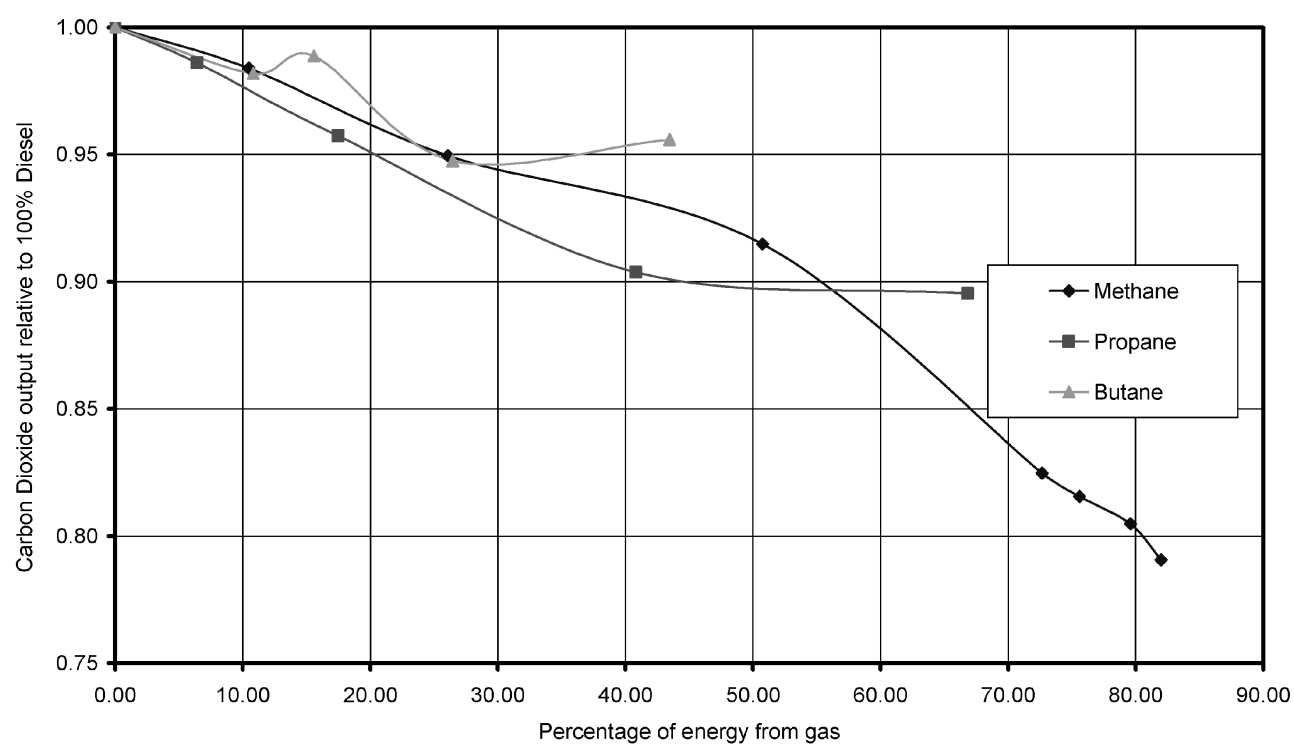

Fig. 13 Brake specific $\mathrm{CO}_{2}$ reductions relative to 100 per cent diesel at three-quarters-load 
the transport sector. A 20 per cent reduction in $\mathrm{CO}_{2}$ engine output is a major aspect of this type of engine if, and only if, the driving public can be made to fill two separate tanks!

6. The ranges of gas substation may be extended, with further $\mathrm{CO}_{2}$ reduction, with the employment of modern fuel injection equipment such as highpressure common-rail and multiple-injection strategies.

\section{REFERENCES}

1 Karim, G. A. The dual-fuel engine of the compression ignition type - prospects, problems and solutions - a review. SAE paper 831073, 1983.

2 Karim, G. A. Combustion in gas fueled compressionignition engines. In Proceedings of the Fall Technical Conference of the ASME Internal Combustion Engine Division, 2000, ICE-Vol. 35-1, pp. 1-10 (American Society of Mechanical Engineers, New York).

3 Krishnan, S. R., Biruduganti, M., Mo, Y., Bell, S. R., and Midkiff, K. C. Performance and heat release analysis of a pilot-ignited natural gas engine. Int. J. Engine Res., 2002, 3(3), 171-184.

4 Patil, P. G. Alternative fuels in future vehicles. Automot. Engng, 1996, 104(1), 39-43.

5 Gebert, K., Beck, N. J., Barkhimer, R. L., and Wong, H. C. Strategies to improve combustion and emission characteristics of dual-fuel pilot ignited natural gas engines. SAE paper 971712, 1997.

6 Lin, Z. and Su, W. A study on the determination of the amount of pilot injection and rich and lean boundaries of the pre-mixed CNG/air mixture for CNG/diesel dual-fuel engine. SAE paper 2003-010765, 2003.

7 Mbarawa, M., Milton, B. E., and Casey, R. T. An investigation of the effects of diesel pilot injection parameters on natural gas combustion under diesel conditions. J. Inst. Energy, 2001, 74, 81-90.

8 Kuo, K. K. Principles of combustion, 2nd edition, 2005 (John Wiley, New York).

9 Bradley, D., Lawes, M., Shepherd, C. G. W., and Woolley, R. Methane as an engine fuel. In Proceedings of the IMechE Seminar on Using natural gas in engines, London, 1996, pp. 9-15 (Mechanical Engineering Publications Limited, London).

10 Park, T., Atkinson, R. J., Clark, N. N., Traver, M. L., and Atkinson, C. M. Operation of a compression ignition engine with a HEUI injection system on natural gas with diesel pilot injection. SAE paper 1999-01-3522, 1999.

11 Liu, B., Checkel, M. D., Hayes, R. E., Zheng, M., and Mirosh, E. Experimental and modelling study of variable cycle time for a reversing flow catalytic conductor for natural gas/diesel dual-fuel engines. SAE paper 2000-01-0213, 2000.

12 Newkirk, M. S., Smith, L. R., Payne, M. L., and Seagal, J. S. Emissions with butane/propane blends. Automot. Engng, 1996, 104(11), 49-54.

13 Pirouzpanah, V. and Nohammadi, A. B. Dualfuelling of an industrial indirect injection diesel engine by diesel and liquid petroleum gas. Int. J. Energy Res., 1996, 20, 903-912.

14 Karim, G. A. and Rogers, A. Comparative studies of propane and butane as dual-fuel engine fuels. J. Inst. Fuel, 1967, 40(322), 513-525.

15 Liu, Z. and Karim, G. A. The ignition delay period in dual-fuel engines. SAE paper 950466, 1995.

16 Goto, S., Furutani, H., Komori, M., and Yagi, M. LPG-diesel engine. Int. J. Veh. Des., 1994, 15(3-5), 279-290.

17 Turner, S. H. and Weaver, C. S. Dual-fuel natural gas/diesel engines: technology, performance, and emissions. Report GRI-94/0094, Gas Research Institute, 1994.

18 Material safety data sheets, 2000 (British Oxygen Co (BOC), Guildford, Surrey).

19 Esso marketing technical bulletin, 2001 (ExxonMobil, Leatherhead, Surrey).

20 Brunt, M. F. J. and Platts, K. C. Calculation of heat release in direct injection diesel engines. SAE paper 1999-01-0187, 1999.

21 Sastry, G. V. J. and Chandra, H. A three-zone heat release model for DI diesel engines. SAE paper 940671, 1994.

22 Stone, R. Introduction to internal combustion engines, 3rd edition, 1999 (Macmillan, Basingstoke).

23 Timoney, D. J., McNally, C. P., and Doyle, C. T. A three-zone heat release model for direct injection diesel engines. In Proceedings of the Conference on Thermofluidynamic processes in diesel engines (THIESEL 2000), Valencia, Spain, 2000, pp. 423-433 (Universidad Politecnica de Valencia, Valencia).

24 Khan, M. O. Dual-fuel combustion phenomena. $\mathrm{PhD}$ Thesis, Imperial College of Science and Technology, London, 1969.

25 Pirouzpanah, V. and Amiraslani, K. A model to predict performance and heat release of dual-fuel diesel engines. In Proceedings of the IMechE Symposium on Gas engines and co-generation, UK, 1990, pp. 69-75 (Mechanical Engineering Publications, London).

26 Liu, Z. and Karim, G. A. Simulation of combustion processes in gas-fuelled diesel engines. Proc. Instn Mech. Engrs, Part A: J. Power and Energy, 1997, 211, 159-169.

27 Press, W. H., Teukolsky, S. A., Vetterling, W. T., and Flannery, B. P. Numerical recipes in Fortran 77: the art of scientific computing, 2nd edition, 1992 (Cambridge University Press, Cambridge).

28 Olikara, C. and Borman, G. L. A computer program for calculating properties of equilibrium combustion with some applications to I.C. engines. SAE paper 750468,1975 